\title{
Current Treatment of Isolated Locoregional Breast Cancer Recurrences
}

\author{
Wolfgang Harms ${ }^{a} \quad$ Andreas Geretschläger $^{a} \quad$ Corinne Cescato $^{b} \quad$ Martin Buess $^{b}$ \\ Dieter Köberle $^{\mathrm{b}}$ Branca Asadpour ${ }^{\mathrm{a}}$
}

${ }^{a}$ Department of Radiation Oncology, St. Claraspital, Basel, Switzerland;

${ }^{b}$ Department of Oncology, St. Claraspital, Basel, Switzerland

\section{Keywords}

Ipsilateral breast tumor recurrence - Local recurrence breast - Locoregional recurrence breast cancer .

Hyperthermia - Radiation therapy · Brachytherapy ·

Chest wall recurrence Breast cancer .

Re-irradiation breast

\section{Summary}

Patients with isolated locoregional breast cancer recurrences should be treated with curative intent. Mastectomy is regarded as the standard of care for patients with ipsilateral breast tumor recurrence. In a selected group of patients, partial breast irradiation after second breastconserving surgery is a viable alternative to mastectomy. If a second breast conservation is performed, additional irradiation should be mandatory, especially in patients who had not been irradiated previously. In case of re-irradiation, the largest experience exists for multi-catheter brachytherapy. Prospective clinical trials are needed to clearly define selection criteria, long-term local control, and toxicity. In patients with resectable locoregional breast cancer recurrences after mastectomy, multi-modal therapy comprising complete resection, radiation therapy in previously unirradiated patients, and systemic therapy results in 5-year disease-free and overall survival rates of $69 \%$ and $88 \%$, respectively. In radiation-naive patients with unresectable, isolated locoregional recurrences, radiation therapy is mandatory. In selected patients with previous irradiations and unresectable locoregional recurrences, a second irradiation as part of an individual treatment concept can be applied. The increased risk of severe toxicity should always be weighed up against the potential clinical benefit. A combination therapy with hyperthermia can further improve the treatment results.

(c) 2015 S. Karger GmbH, Freiburg

\section{Introduction}

Treatment of locally recurrent breast cancer remains an interdisciplinary challenge since treatment options are limited or at least restricted due to previous treatments. Data from large, randomized trials have demonstrated that locoregional recurrences occur in approximately $5-15 \%$ of patients, despite treatment with adjuvant radiotherapy after mastectomy or breast-conserving surgery (BCS) [1-5]. The most common site of recurrence after adjuvant radiotherapy is the ipsilateral breast or the chest wall, comprising 60$95 \%$ of all locoregional recurrences [6, 7]. Locoregional recurrences are typically associated with an increased risk of concurrent or subsequent systemic relapse $[8,9]$. Especially early recurrences within the first 2 years after primary treatment seem to have a worse prognosis [9]. This publication addresses indications for radiotherapy of isolated locoregional breast cancer recurrences.

\section{Therapy of Ipsilateral Breast Tumor Recurrence}

BCS followed by adjuvant radiotherapy has become the standard of care for the majority of breast cancer patients. Ipsilateral breast tumor recurrence (IBTR) is diagnosed in approximately $5-10 \%$ of patients at 10 years after breast-conserving therapy (BCT) [10-13]. International guidelines recommend mastectomy as standard treatment for IBTR after BCT [14-16]. Salvage mastectomy results in locoregional control rates of $69-98 \%$ and 5-year survival rates of $53-85 \%[17,18]$. Nevertheless, this approach is not founded on solid data indicating a clear advantage of radical surgery for IBTR for all patients compared to a second attempt of BCT [19]. There are no published or ongoing prospective studies comparing mastectomy versus repeat BCS alone in patients with IBTR. Published data are limited and most series reporting on a second conservative approach with or without the addition of adjuvant radiotherapy are single-institution retrospective studies. The Radiation Therapy On-

\section{KARGER \\ Fax +497614520714

\section{(c) 2015 S. Karger GmbH, Freiburg}

1661-3791/15/0104-0265\$39.50/0
Prof. Dr. med. Wolfgang Harms

Abteilung für Radioonkologie

St. Claraspital

Kleinriehenstrasse 30, 4016 Basel, Switzerland

wolfgang.harms@claraspital.ch 
cology Group (RTOG) introduced in 2010 a phase II prospective trial of repeat BCS adding 3-dimensional (3D) conformal partial breast re-irradiation for local recurrence [20]. Additionally, a mutilating rescue surgery causes enormous emotional and physical distress for the patients $[21,22]$. The currently implemented close follow-up routine has led to the detection of IBTR at early stages, technically amenable to a second breast-conserving approach. Thus, the question remains if subgroups of patients can be defined who might benefit from a second breast-conserving approach. Unfortunately, no prospective data have been published so far.

Definition of True IBTRs and Selection Criteria for a Second BCT

Veronesi et al. [23] suggested that patients with IBTR constitute a heterogeneous group with true tumor recurrences and new primary tumors. In a large retrospective study on 1,410 patients, Gujral et al. [24] reported a cumulative incidence rate of new primaries after whole-breast irradiation at 5,10 , and 15 years of $0.8 \%$, $2 \%$, and $3.5 \%$, respectively. The authors concluded that wholebreast irradiation approximately halves the rate of new primaries. In a retrospective study on 136 patients with IBTR as the first site of failure, Smith et al. [25] reported a significantly improved 10year overall survival (OS) in patients with new primaries (75\%) compared to patients with true recurrences (55\%). This question has been addressed in several studies attempting to differentiate between true recurrences and new primaries [25-28], from which the following conclusions can be derived: The majority of IBTRs are true recurrences, which tend to occur earlier and in the same quadrant as the initial tumor, metastasize earlier and more often

Table 1. Possible selection criteria for patients who may be candidates for a second breast-conserving approach

Isolated ipsilateral breast tumor recurrence

Limited size $(<2-3 \mathrm{~cm})$

Unifocal disease on ultrasound, mammography, and magnetic resonance imaging

Age $\geq 50$ years

Long interval between primary treatment and recurrence ( $\geq 48$ months)

Desire of the patient for a second breast conservation followed by radiotherapy

A second breast conservation is technically feasible and will result in acceptable cosmetic results

Table 2. Outcomes of patients treated with repeat BCS alone following IBTR and result in a shorter OS and disease-free survival (DFS) than new primaries. Further retrospective studies [29-31] evaluating IBTRs showed that there are subgroups of patients with improved rates of OS, DFS, and second local recurrence. Based on these retrospective studies, selection criteria for patients who may be candidates for a second breast-conserving approach are summarized in table 1.

However, repeat BCS alone is associated with increased local failure rates, ranging between $19-38 \%$ (table 2) [32]. Recent studies showed promising OS rates in selected patients treated with second conservative surgery followed by partial breast irradiation (PBI) $[33,34]$. The following survey of techniques and results provides an overview of the different techniques and the current status of radiation therapy for IBTR (table 3).

\section{Brachytherapy after BCS for IBTR}

The most solid evidence for re-irradiation of IBTRs exists for brachytherapy (BT). The GEC-ESTRO working group [34] (Groupe Européen de Curiethérapie (GEC) combined with the European Society for Radiotherapy \& Oncology (ESTRO)) reported on a retrospective collaborative analysis of 217 patients with IBRT treated between 2000 and 2009 in 8 European institutions by multi-catheter BT [34]. The median total dose delivered through low-dose rate (LDR) and pulsed-dose rate (PDR) BT was $46 \mathrm{~Gy}$ (range: 30-55 Gy) and 50.4 Gy (range: 49-50 Gy), respectively, and 32 Gy (range: 22-36 Gy) (equivalent dose in 2-Gy fractions (EQD2) 43 Gy) in 5-10 (median: 8) fractions (twice daily) for high-dose rate (HDR) BT. With a median follow-up of 3.9 years (1.1-10.3 years) after IBTR re-treatment, the 5- and 10-year actuarial 2nd local recurrence rates were 5.6\% (1.5-9.5\%) and 7.2\% (2.1-12.1\%), respectively. In comparison with salvage mastectomy series, the results were reported to be at least equivalent, with 5and 10 -year actuarial rates for metastatic recurrence of $9.6 \%$ and $19.1 \%$, DFS rates of $84.6 \%$ and $77.2 \%$, and OS rates of $88.7 \%$ and $76.4 \%$, respectively. Further single-institution studies with small patient numbers support these data [35-38].

\section{External-Beam Radiotherapy after BCS for IBTR}

There is a single report on external-beam radiotherapy (EBRT) for the treatment of IBTR [39] comprising 39 patients. Retreatment was performed by using electrons in single fractional doses of 2 up to $50 \mathrm{~Gy}$ to the involved quadrant. At a median follow-up of 51.5

\begin{tabular}{lllll}
\hline Study/year & $\begin{array}{l}\text { Number of } \\
\text { patients }\end{array}$ & $\begin{array}{l}\text { Median follow-up, } \\
\text { months }\end{array}$ & $\begin{array}{l}\text { Local recurrence } \\
\text { rate, } \%\end{array}$ & $\begin{array}{l}5 \text {-year OS, } \\
\%\end{array}$ \\
\hline $\begin{array}{l}\text { Salvadori et al. 1999 } \\
\quad \text { 69] }\end{array}$ & 57 & 73 & 19 & 85 \\
$\begin{array}{l}\text { Voogd et al. 1999 } \\
\text { [70] }\end{array}$ & 16 & 52 & 38 & NR \\
$\begin{array}{l}\text { Ishitobi et al. 2011 } \\
\text { [71] }\end{array}$ & 78 & 40 & 21 & NR \\
$\begin{array}{l}\text { Gentilini et al. 2012 } \\
\text { [72] }\end{array}$ & 161 & 81 & 29 & 84 \\
\hline NR = Not reported, BCS = breast conserving surgery, OS = overall survival. &
\end{tabular}

$\mathrm{NR}=$ Not reported, $\mathrm{BCS}=$ breast conserving surgery, $\mathrm{OS}=$ overall survival 
Table 3. Outcomes of patients treated with repeat BCS and radiotherapy following IBTR

Table 4. Outcomes of patients with locoregional chest wall recurrences treated with repeat irradiation \pm hyperthermia

\begin{tabular}{|c|c|c|c|c|c|c|c|}
\hline Study/Year & Patients, $\mathrm{n}$ & $\begin{array}{l}\text { Median follow- } \\
\text { up, months }\end{array}$ & RT technique & $\begin{array}{l}\text { Repeat RT } \\
\text { dose, Gy }\end{array}$ & $\begin{array}{l}\text { Toxicity grade } \\
3 / 4, \%\end{array}$ & $\begin{array}{l}\text { Local } \\
\text { control, \% }\end{array}$ & OS, \% \\
\hline Deutsch 2002 [73] & 39 & 51.5 & EBRT & 50 & NR & 77 & 78 \\
\hline $\begin{array}{c}\text { Kraus-Tiefenbacher } \\
\text { et al. } 2007 \text { [41] }\end{array}$ & 15 & 26 & IORT & 20 & 0 & 100 & 93 \\
\hline $\begin{array}{l}\text { Chadha et al. } 2008 \\
\text { [37] }\end{array}$ & 15 & 36 & BT & 30 or 45 & 0 & 89 & 100 \\
\hline Guix et al. 2010 [42] & 36 & 89 & BT & 30 & 0 & $89^{\mathrm{a}}$ & $97^{\mathrm{a}}$ \\
\hline $\begin{array}{l}\text { Kauer-Dorner et al. } \\
\quad 2012 \text { [36] }\end{array}$ & 39 & 57 & BT & 50 & $17 / 0$ & 93 & 87 \\
\hline $\begin{array}{l}\text { Hannoun-Levi et al. } \\
2013 \text { [34] }\end{array}$ & 217 & 46.8 & BT & $\begin{array}{l}\text { LDR } 46 \\
\text { PDR } 50.4 \\
\text { HDR } 32\end{array}$ & 11 & $93^{\mathrm{a}}$ & $76^{\mathrm{a}}$ \\
\hline
\end{tabular}

$\mathrm{RT}=$ Radiotherapy, $\mathrm{OS}=$ overall survival, $\mathrm{EBRT}=$ external-beam radiotherapy, $\mathrm{IORT}=$ intraoperative radiotherapy, $\mathrm{BT}=$ brachytherapy, $\mathrm{LDR}=$ low dose rate, $\mathrm{PDR}=$ pulsed dose rate, $\mathrm{HDR}=$ high dose rate, $\mathrm{NR}=$ not reported, $\mathrm{BCS}=$ breast conserving surgery. ${ }^{\mathrm{a}} 10$-year actuarial.

\begin{tabular}{|c|c|c|c|c|c|c|}
\hline Study & $\begin{array}{l}\text { Patients, } \\
\mathrm{n}\end{array}$ & $\begin{array}{l}\text { Initial dose, } \\
\text { Gy }\end{array}$ & RT technique & $\begin{array}{l}\text { Repeat dose, } \\
\text { Gy }\end{array}$ & $\begin{array}{l}\text { Complete } \\
\text { remission, \% }\end{array}$ & Toxicity grade (\%) \\
\hline Delanian et al. [74] & 11 & $45-65$ & BT & 60 & 81.8 & $\begin{array}{l}2 / 3(45 \%) \\
4(9 \%)\end{array}$ \\
\hline Harms et al. [65] & 58 & $36-70$ & BT & $2 \times 20$ & 79.3 & $\begin{array}{l}3\left(60 \%{ }^{b}\right) \\
4(7 \%)\end{array}$ \\
\hline Laramore et al. [53] & 13 & $40-50$ & EBRT & $40-50$ & 61.5 & $\begin{array}{l}3(0 \%) \\
4(0 \%)\end{array}$ \\
\hline $\begin{array}{l}\text { Phromratana-pongse } \\
\text { et al. [56] }\end{array}$ & 44 & $35-66$ & $\mathrm{EBRT}+\mathrm{HT}$ & $16-56$ & 40.9 & $\begin{array}{l}3(25 \%) \\
4(\mathrm{NR})\end{array}$ \\
\hline Li et al. [75] & 41 & 58 & EBRT & 43 & 56 & $4(8 \%)$ \\
\hline Jones et al. ${ }^{\mathrm{a}}[67]$ & $\begin{array}{l}52 \\
56\end{array}$ & NR & $\begin{array}{l}\text { EBRT } \\
\mathrm{EBRT}+\mathrm{HT}\end{array}$ & $\begin{array}{l}30-66 \\
60-70\end{array}$ & $\begin{array}{l}42.3 \\
66.1\end{array}$ & $\begin{array}{l}3(2 \%) \\
3(5 \%)\end{array}$ \\
\hline Kouloulias et al. [76] & 15 & 60 & $\mathrm{EBRT}+\mathrm{HT}$ & 30.6 & 20 & $\begin{array}{l}3(\mathrm{NR}) \\
4(7 \%)\end{array}$ \\
\hline Linthorst et al. [60] & 198 & 48 & $\mathrm{EBRT}+\mathrm{HT}$ & $8 \times 4$ & $78^{c}$ & $3 / 4\left(11.9 \%{ }^{\mathrm{d}}\right)$ \\
\hline Linthorst et al. [68] & 248 & 49 & $\mathrm{EBRT}+\mathrm{HT}$ & $8 \times 4$ & $39^{c}$ & $3\left(1 \%{ }^{\mathrm{d}}\right)$ \\
\hline
\end{tabular}

$\mathrm{RT}=$ Radiotherapy, $\mathrm{BT}=$ brachytherapy, EBRT = external-beam radiotherapy, $\mathrm{HT}=$ hyperthermia, $\mathrm{NR}=$ not reported. ${ }^{a}$ Breast cancer and other tumor entities.

bPredominantly telangiectasia.

c5-year local control rate.

d5-year rate. months, 30 women (76.9\%) had an intact breast free of tumor. The RTOG started a phase II study of repeat breast-preserving surgery and 3D conformal partial breast re-irradiation (PBI) for local recurrence of breast carcinoma with single doses of $1.5 \mathrm{~Gy}$ in 15 fractions twice daily for a total dose of $45 \mathrm{~Gy}$ [40]. The study has reached the accrual goal of 61 patients and is closed, but not published.

\section{Intraoperative Radiotherapy after BCS for IBTR}

There is only 1 publication considering intraoperative radiotherapy (IORT) for re-irradiation of IBRT [41]. 15 patients were treated applying IORT with $50-\mathrm{kV} \mathrm{X}$-rays in single dosages of 14.7-20 Gy (applicator surface). At a medium follow-up of 26 months (1-60 months), no local recurrence occurred.

\section{Toxicity Assessment/Cosmetic Outcome}

In all publications, acute toxicities of the respective method were reported to be low while the most frequent late reaction pattern was fibrosis. Especially when assessed by standardized scoring systems, grade 1-2 sequelae in terms of fibrosis, telangiectasia and/ or pain ranged between 44 and 79\%, respectively [41-43]. Grade 3 late reactions were observed in $0-17 \%$ (table 3 ) and in most of the cases comprised breast tissue fibrosis and breast pain [34, 42]. The range may be explained by the application of different treatment techniques and regimes and small patient numbers. Severe late reactions like skin necrosis or ulceration were hardly ever stated. In the GEC-ESTRO series of 217 patients, 141 patients (65\%) developed late complications: cutaneous and subcutaneous fibrosis 
(67\%), telangiectasia (16\%), hyperpigmentation (9\%), and ulceration (1\%). Grade 3 and 4 complications were reported in $10 \%$ and $1 \%$, respectively. The cosmetic results in the GEC-ESTRO series were assessed in 109 patients (50.2\%) and were rated excellent in $52(48 \%)$, good in $40(37 \%)$, fair in $14(13 \%)$, and poor in $2(2 \%)$ patients [34].

\section{Conclusions for the Therapy of Ipsilateral Breast Cancer Recurrences}

Even though mastectomy is regarded as the standard of care for patients with IBTR, in a selected group of patients PBI after second BCS is a viable alternative to mastectomy. This approach yields high breast preservation rates and does not seem to compromise oncologic safety. If a second breast conservation is performed, additional irradiation should be mandatory, even more so in patients who had not been irradiated previously. In case of re-irradiation, so far the largest experience exists for multi-catheter BT. There is only limited information on the effectiveness of EBRT or IORT, which should be preferentially performed in clinical trials. Prospective clinical trials are needed to clearly define selection criteria, long-term local control, and toxicity.

\section{Therapy of Isolated Locoregional Recurrences after Mastectomy}

\section{Definition and Patterns of Recurrence}

A locoregional breast cancer recurrence after mastectomy is defined as the appearance of tumor in the ipsilateral chest wall or in axillary, internal mammary, or supraclavicular lymph nodes [8]. The Early Breast Cancer Trialists' Collaborative Group analysis revealed a 10-year risk of an isolated locoregional recurrence as the first event after mastectomy of $20.3 \%$ for patients with $1-3$ positive axillary lymph nodes, and of $32.1 \%$ for patients with 4 or more positive nodes. The addition of radiotherapy significantly reduced the risk to 3.8 and $13 \%$, respectively [2, 44-46]. In a retrospective study, Katz et al. [47] reported on the local recurrence patterns of 1,031 women treated in 5 prospective trials with mastectomy and adjuvant chemotherapy without radiation therapy. After a median follow-up of 116 months, the most common sites of isolated locoregional recurrences were at the chest wall and the supraclavicular lymph nodes.

\section{Treatment of Resectable Recurrences}

If no previous irradiation has been performed, the optimal treatment consists of complete excision of the gross disease followed by irradiation $[8,39]$. This approach has improved local control [48] and may have an effect on survival [49]. In a retrospective study on 159 patients with an isolated locoregional recurrence after mastectomy, Skinner et al. [50] reviewed the effects of a dose escalation on local control and survival. The patients in the standard treatment group were treated to a dose of 50 Gy plus a boost of $10 \mathrm{~Gy}$, while the dose escalation group was treated to a dose of 54 Gy plus a 12 Gy boost. The authors observed for the entire group a $77 \%$ locoregional control rate (LCR) and a 55\% OS rate at 5 years. OS and LCR were not significantly improved in the dose escalation group. In summary, patients with an isolated locoregional recurrence after mastectomy should undergo surgical resection of the local recurrence and radiation therapy to the chest wall and supraclavicular lymph nodes. If no previous irradiation has been performed, a standard dose of 50-50.4 Gy with 1.8/2-Gy fractions should be applied. An additional boost dose of $10 \mathrm{~Gy}$ can be applied, especially if risk factors are present.

For systemic management, endocrine therapy should be administered to all receptor-positive patients [51]. In a prospective randomized study, Aebi et al. [52] investigated the effects of chemotherapy in 162 patients with completely resected isolated locoregional breast cancer recurrences. The authors found that adjuvant chemotherapy in addition to radiation and endocrine therapy prolonged the DFS and OS, in particular in patients with estrogen receptornegative locoregional relapse. The 5-year DFS and OS rates were $69 \%$ and $88 \%$, respectively. This result challenges the current practice of inconsistent use of chemotherapy and provides evidence in favor of offering adjuvant chemo- and radiotherapy to women with completely resected isolated locoregional relapse of breast cancer.

\section{Treatment of Unresectable Recurrences}

In patients with unresectable, isolated locoregional recurrences who were not previously irradiated, radiation therapy is mandatory. In a retrospective study, Skinner et al. [50] reported that patients with gross disease at the time of radiation had a significantly lower 5 -year local control (63\%) and survival rate (34\%) compared to patients with no residual disease after surgery or systemic therapy ( $81 \%$ and $62 \%$, respectively). If a complete remission after radiation therapy was accomplished, the 5-year survival rate increased from $27 \%$ to $62 \%$ [50]. Therefore, the same recommendations for radiation and endocrine therapy apply as for resectable disease. The boost dose can be increased depending on the size and the location of the recurrence. The indication for an additional chemotherapy should be defined on an individual basis since no prospective data are available. In summary, multi-modal therapy including systemic therapy and radiation therapy has the potential to cure selected patients $[9,49]$.

\section{Therapy of Isolated Locoregional Recurrences after Mastectomy and Adjuvant Radiotherapy}

In patients with isolated locoregional recurrences after mastectomy and adjuvant radiotherapy, the treatment options are limited. If a complete resection is possible, surgery should be accomplished, but heroic surgery with problems to cover the tissue defect or prolonged wound healing problems should be avoided. Unfortunately, most of the patients present with advanced disease. Systemic therapy is a treatment option, especially when concurrent distant metastases are present. Re-irradiation is used with caution due to an increased normal-tissue complication probability. Thus, only few series using EBRT alone [53-55] or in combination with hyperthermia for re-irradiation of the chest wall have been published so 
far [56-61]. Additionally, simultaneous radiochemotherapy as a further treatment option has been investigated in a limited number of trials [62-64].

\section{Re-Irradiation}

Laramore et al. [53] reported on 13 patients treated with conventionally fractionated electrons for chest wall recurrences. All patients had received previous postoperative chest wall irradiation of 40-50 Gy. $62 \%$ of the patients were alive and free of local disease after a median follow-up of 12 months. The skin reactions were restricted to temporary erythema and dry or moist desquamation. In a retrospective study, Harms et al. [65] reported on 58 patients treated with PDR BT molds. The local control rate was $79 \% .10 \%$ of the patients experienced grade 3 fibrosis and $7 \%$ grade 4 late effects.

\section{Re-Irradiation in Combination with Hyperthermia}

A further approach to enhance radiation effectiveness is the additional use of hyperthermia. This combination has improved clinical response and local control in several phase II studies and randomized trials [66]. Jones et al. [67] enrolled 109 patients with superficial tumors (70 patients with breast cancer) in a prospective randomized trial comparing irradiation of chest wall recurrences with irradiation and additional hyperthermia. The complete response rate was $66.1 \%$ in the hyperthermia arm and $42.3 \%$ in the irradiation alone arm. Previously irradiated patients had the greatest incremental gain in complete response: $23.5 \%$ in the non-hyperthermia versus $68.2 \%$ in the hyperthermia arm. No OS benefit was seen. The authors concluded that adjuvant hyperthermia conferred a significant local control benefit to patients with superficial tumors receiving radiation therapy. In a retrospective analysis on 198 patients who underwent either R0 $(\mathrm{n}=107)$ or R1 resection ( $\mathrm{n}$ $=91)$, hyperthermia was used as an adjunct to re-irradiation $(8 \times 4$
Gy) [60]. After a median follow-up of 42 months, the 5-year LCR was $78 \%$. The 5 -year grade $3 / 4$ late toxicity rate amounted to $11.9 \%$ ( $\mathrm{n}=15$ skin ulcerations, $\mathrm{n}=5$ osteoradionecrosis of the ribs). The same working group investigated 248 patients with macroscopic breast cancer recurrence treated with re-irradiation and hyperthermia [68]. After a median follow-up period of 32 months, $70 \%$ of the patients had a complete remission. The 5-year local control rate was $39 \%$. $23 \%$ of the patients developed thermal burn, which healed with conservative measures. The incidence of 5-year late grade 3 toxicity was $1 \%$ (table 4 ).

\section{Conclusions for the Therapy of Locoregional Recurrences after Mastectomy}

Multi-modal therapy including systemic therapy, surgery, and radiation \pm hyperthermia achieves a high rate of local control and can be curative with long-term survival in a subset of patients. In previously not irradiated patients, the chest wall and regional lymph nodes should be treated with doses of 50-50.4 Gy (1.8-2 Gy per day). A boost dose of 10 Gy may be applied. Further dose escalation does not seem to improve the treatment results.

In selected patients with previous irradiations and unresectable locoregional recurrence, a second irradiation as part of an individual multi-modal treatment concept can be applied. The increased risk of severe acute and late toxicity should always be weighed up against the potential clinical benefit. Especially in previously irradiated patients, a combination therapy with hyperthermia can further improve the local control rates and spare dose.

\section{Disclosure Statement}

W.H., A.G., C.C., M.B., D.K., and B.A. declare no conflict of interest.

\section{References}

1 Early Breast Cancer Trialists' Collaborative Group (EBCTCG): Effect of radiotherapy after breast-conserving surgery on 10-year recurrence and 15-year breast cancer death: meta-analysis of individual patient data for 10801 women in 17 randomised trials. Lancet 2011;378:1707-1716.

$\checkmark 2$ Early Breast Cancer Trialists' Collaborative Group (EBCTCG): Effect of radiotherapy after mastectomy and axillary surgery on 10-year recurrence and 20-year breast cancer mortality: meta-analysis of individual patient data for 8135 women in 22 randomised trials Lancet 2014;383:2127-2135.

3 Christiansen P, Al Suliman N, Bjerre K, Moller S: Recurrence pattern and prognosis in low-risk breast cancer patients - data from the DBCG 89-A programme. Acta Oncol 2008;47:691-703.

4 Bartelink H, Maingon P, Poortmans P, et al.: Wholebreast irradiation with or without a boost for patients treated with breast-conserving surgery for early breast cancer: 20-year follow-up of a randomised phase 3 trial. Lancet Oncol 2015;16:47-56.

5 Sedlmayer F, Sautter-Bihl ML, Budach W, et al.: DEGRO practical guidelines: radiotherapy of breast cancer I: radiotherapy following breast conserving therapy for invasive breast cancer. Strahlenther Onkol 2013;189:825-833.
6 Wahl AO, Rademaker A, Kiel K, et al.: Multi-institutional review of repeat irradiation of chest wall and breast for recurrent breast cancer. Int J Radiat Oncol Biol Phys 2008;70:477-484

7 Danish Breast Cancer Cooperative Group, Nielsen HM, Overgaard M, Grau C, et al.: Study of failure pattern among high-risk breast cancer patients with or without post-mastectomy radiotherapy in addition to adjuvant systemic therapy: long term results from the Danish Breast Cancer Cooperative Group DBCG 82 b and c randomized studies. J Clin Oncol 2006;24:2268-2275.

$>8$ Bedwinek J: Natural history and management of isolated local-regional recurrence following mastectomy. Semin Radiat Oncol 1994;4:260-269.

$\checkmark$ van Tienhoven G, Voogd AC, Peterse JL, et al.: Prognosis after treatment for locoregional recurrence after mastectomy or breast conserving therapy in two randomised trials (EORTC 10801 and DBCG-82TM). EORTC Breast Cancer Cooperative Group and the Danish Breast Cancer Cooperative Group. Eur J Cancer 1999,35:32-38.

10 Fisher B, Anderson S, Bryant J, et al.: Twenty-year follow-up of a randomized trial comparing total mastectomy, lumpectomy, and lumpectomy plus irradiation for the treatment of invasive breast cancer. N Engl J Med 2002;347:1233-1241.
11 Wapnir IL, Anderson SJ, Mamounas EP, et al.: Prognosis after ipsilateral breast tumor recurrence and locoregional recurrences in five National Surgical Adjuvant Breast and Bowel Project node-positive adjuvant breast cancer trials. J Clin Oncol 2006;24:2028-2037.

12 Bouganim M, Tsetkova E, Clemons M, et al.: Evolution of sites of recurrence after early breast cancer over the last 20 years: implications for patient care and future research. Breast Cancer Res Treat 2013;139:603-606.

13 Sedlmayer F, Sautter-Bihl ML, Budach W, et al.: DEGRO practical guidelines: radiotherapy of breast cancer I: radiotherapy following breast conserving therapy for invasive breast cancer. Breast Cancer Expert Panel of the German Society of Radiation Oncology (DEGRO). Strahlenther Onkol 2013;189:825-833.

14 Interdisziplinäre S3-Leitlinie für die Diagnostik, Therapie und Nachsorge des Mammakarzinoms. Langversion 3.0, Aktualisierung 2012. www.leitlinienprogrammonkologie.de.

15 National Comprehensive Cancer Network Clinica Practice Guidelines in Oncology: Breast Cancer. $w w w$. nccn.org/professionals/physician_gls/pdf/breast.pdf [last accessed April 13, 2015]. 
16 Wenz F, Sperk E, Budach W, et al.: DEGRO practical guidelines for radiotherapy of breast cancer IV: radiotherapy following mastectomy for invasive breast cancer. Strahlenther Onkol 2014;190:705-714.

17 Anderson SJ, Wapnir I, Dignam JJ: Prognosis after ipsilateral breast tumor recurrence and locoregional recurrences in patients treated by breast conserving therapy in five National Surgical Adjuvant Breast and Bowel Project protocols of node-negative breast cancer. J Clin Oncol 2009;27:2466-2473.

18 Fowble B, Solin LJ, Schultz DJ, et al.: Breast recurrence following conservative surgery and radiation: patterns of failure, prognosis, and pathologic findings from mastectomy specimens with implications for treatment. Int J Radiat Oncol Biol Phys 1990;19:833-842.

19 Vila J, Garcia-Etienne CA, Vavassori A, Gentilini O: Conservative surgery for ipsilateral breast tumor recurrence. J Surg Oncol 2014;110:62-67.

20 RTOG 1014: Radiation therapy in treating women with locally recurrent breast cancer previously treated with repeat breast-preserving surgery. https://clinicaltrials.gov/ct2/results?term $=01082211$.

21 Sautter-Bihl ML, Sedlmayer F, Budach W, et al.: When are breast cancer patients old enough for the quitclaim of local control? Strahlenther Onkol 2012;188:10691073.

22 Kirchheiner K, Czajka A, Ponocny-Seliger E, et al.: Validation and practical implementation of a multidisciplinary cancer distress screening questionnaire. Strahlenther Onkol 2013;189:573-578

23 Veronesi U, Marubini E, Del Vecchio M, et al.: Local recurrences and distant metastases after conservative breast cancer treatments: partly independent events. J Natl Cancer Inst 1995;87:19-27.

24 Gujral DM, Sumo G, Owen JR, et al.: Ipsilateral breast tumor relapse: local recurrence versus new primary tumor and the effect of whole breast radiotherapy on the rate of new primaries. Int J Radiat Oncol Biol Phys 2011;79:19-25.

25 Smith TE, Lee D, Turner BC, Carter D, Haffty BG: True recurrence vs. new primary ipsilateral breast tumor relapse: an analysis of clinical and pathologic differences and their implications in natural history, prognoses, and therapeutic management. Int J Radiat Oncol Biol Phys 2000;48:1281-1289.

26 Komoike Y, Akiyama F, Iino Y, et al.: Analysis of ipsilateral breast tumor recurrences after breast-conserving treatment based on the classification of true recurrences and new primary tumors. Breast Cancer 2005; 12:104-111.

27 Huang E, Buchholz TA, Meric F, et al.: Classifying local disease recurrences after breast conservation therapy based on location and histology: new primary tumors have more favorable out-comes than true local disease recurrences. Cancer 2002;95:2059-2067.

28 Nishimura S, Takahashi K, Akiyama F, et al.: Classification of ipsilateral breast tumor recurrence after breast-conserving therapy: new primary cancer allows a good prognosis. Breast Cancer 2005; 12:112-117.

29 Fodor J, Major T, Polgár C, et al.: Prognosis of patients with local recurrence after mastectomy or conservative surgery for early-stage invasive breast cancer. Breast 2008;17:302-308.

30 van Laar C, van der Sangen MJ, Poortmans PM, et al.: Local recurrence following breast-conserving treatment in women aged 40 years or younger: trends in risk and the impact on prognosis in a populationbased cohort of 1143 patients. Eur J Cancer 2013;49: 3093-3101.

31 Miles RC, Gullerud RE, Lohse CM, et al.: Local recurrence after breast-conserving surgery: multivariable analysis of risk factors and the impact of young age. Ann Surg Oncol 2012;19:1153-1159.
32 Alpert TE, Kuerer HM, Arthur DW, et al.: Ipsilateral breast tumor recurrence after breast conservation therapy: outcomes of salvage mastectomy vs. salvage breast-conserving surgery and prognostic factors for salvage breast preservation. Int J Radiat Oncol Biol Phys 2005;63:845-851.

33 Sedlmayer F, Zehentmayr F, Fastner G: Partial breast re-irradiation for local recurrence of breast carcinoma: benefit and long term side effects. Breast 2013;22(suppl 2):S141-S146.

34 Hannoun-Levi JM, Resch A, Gal J, et al.: Accelerated partial breast irradiation with interstitial brachytherapy as second conservative treatment for ipsilateral breast tumour recurrence: multicentric study of the GEC-ESTRO Breast Cancer Working Group. Radiother Oncol 2013;108:226-231.

35 Resch A, Fellner C, Mock U, et al.: Locally recurrent breast cancer: pulse dose rate brachytherapy for repeat irradiation following lumpectomy - a second chance to preserve the breast. Radiology 2002;225:713-718.

36 Kauer-Dorner D, Pötter R, Resch A, et al.: Partial breast irradiation for locally recurrent breast cancer within a second breast conserving treatment: alternative to mastectomy? Results from a prospective trial. Radiother Oncol 2012;102:96-101.

37 Chadha M, Feldman S, Boolbol S, et al.: The feasibility of a second lumpectomy and breast brachytherapy for localized cancer in a breast previously treated with lumpectomy and radiation therapy for breast cancer. Brachytherapy 2008;7:22-28.

38 Trombetta M, Julian T, Bhandari T, et al.: Breast conservation surgery and interstitial brachytherapy in the management of locally recurrent carcinoma of the breast: the Allegheny General Hospital experience. Brachytherapy 2008;7:29-36.

39 Schwaibold F, Fowble BL, Solin LJ, Schultz DJ, Goodman RL: The results of radiation therapy for isolated local regional recurrence after mastectomy. Int J Radiat Oncol Biol Phys 1991;21:299-310.

40 http://www.rtog.org/clinicaltrials/protocoltable/ studydetails.aspx?study=1014

41 Kraus-Tiefenbacher U, Bauer L, Scheda A, et al.: Intraoperative radiotherapy (IORT) is an option for patients with localized breast recurrences after previous external-beam radiotherapy. BMC Cancer 2007;7:178.

42 Guix B, Lejárcegui JA, Tello JI, et al.: Exeresis and brachytherapy as salvage treatment for local recurrence after conservative treatment for breast cancer: results of a ten-year pilot study. Int J Radiat Oncol Biol Phys 2010;78:804-810.

43 Hannoun-Levi JM, Castelli J, Plesu A, et al.: Second conservative treatment for ipsilateral breast cancer recurrence using high-dose rate interstitial brachytherapy: preliminary clinical results and evaluation of patient satisfaction. Brachytherapy 2011;10:171-177.

44 Budach W, Matuschek C, Bölke E, et al.: DEGRO practical guidelines for radiotherapy of breast cancer $\mathrm{V}$ : Therapy for locally advanced and inflammatory breast cancer, as well as local therapy in cases with synchronous distant metastases. Strahlenther Onkol 2015;191: 623-633.

45 Sautter-Bihl ML, Sedlmayer F, Budach W, et al.: DEGRO practical guidelines: radiotherapy of breast cancer III - radiotherapy of the lymphatic pathways. Strahlenther Onkol 2014;190:342-351.

46 Sautter-Bihl ML, Sedlmayer F, Budach W, et al.: How nescience may obscure evidence. Strahlenther Onkol 2014;190:861-863.

47 Katz A, Strom EA, Buchholz TA, et al.: Locoregional recurrence patterns after mastectomy and doxorubicin-based chemotherapy: implications for postoperative irradiation. J Clin Oncol 2000;18:2817-2827.
48 Halverson K, Perez C, Kuske R, et al.: Isolated localregional recurrence of breast cancer following mastectomy: radiotherapeutic management. Int J Radiat Oncol Biol Phys 1990;19:851-858.

49 Chagpar A, Kuerer HM, Hunt KK, Strom EA, Buchholz TA: Outcome of treatment for breast cancer patients with chest wall recurrence according to initial stage: implications for post-mastectomy radiation therapy. Int J Radiat Oncol Biol Phys 2003;57:128-135.

50 Skinner HD, Strom EA, Motwani SB, et al.: Radiation dose escalation for locoregional recurrence of breast cancer after mastectomy. Radiat Oncol 2013;8:13.

51 Borner M, Bacchi M, Goldhirsch A, et al.: First isolated locoregional recurrence following mastectomy for breast cancer: results of a phase III multicenter trial comparing systemic treatment with observation after excision and radiation. J Clin Oncol 1994;12:2071-2077.

52 Aebi S, Gelber S, Anderson SJ: Chemotherapy for isolated locoregional recurrence of breast cancer: the CALOR randomised trial. Lancet Oncol 2014;15:156163.

53 Laramore GE, Griffin TW, Parker RG, Gerdes AJ: The use of electron beams in treating local recurrence of breast cancer in previously irradiated fields. Cancer 1978;41:991-995.

54 Elkort RJ, Kelly W, Mozden PJ, Feldman MI: A combined treatment program for the management of locally recurrent breast cancer following chest wall irradiation. Cancer 1980;46:647-653.

55 Wahl AO, Rademaker A, Kiel KD, et al.: Multi-institutional review of repeat irradiation of chest wall and breast for recurrent breast cancer. Int J Radiat Oncol Biol Phys 2008;70:477-484.

56 Phromratanapongse P, Steeves RA, Severson SB, Paliwal BR: Hyperthermia and irradiation for locally recurrent previously irradiated breast cancer. Strahlenther Onkol 1991;167:93-97.

57 Van der Zee J, van der Holt B, Rietveld PJM, et al.: Reirradiation combined with hyperthermia in recurrent breast cancer is a worthwhile local palliation. Br J Cancer 1999;79:483-490.

58 Amicheti M, Valdagni R, Graiff C, Valentini A: Localregional recurrences of breast cancer: treatment with radiation therapy and local microwave hyperthermia. Am J Clin Oncol 1991;14:60-65.

59 Kapp DS, Cox RC: Thermal treatment parameters are most predictive of outcome in patients with single tumor nodules per treatment field in recurrent adenocarcinoma of the breast. Int J Radiat Oncol Biol Phys 1995;33:887-899.

60 Linthorst M, van Geel AN, Baaijens M, et al.: Re-irradiation and hyperthermia after surgery for recurrent breast cancer. Radiother Oncol 2013;109:188-193.

61 Linthorst M, van Geel AN, Baartman EA, et al.: Effect of a combined surgery, re-irradiation and hyperthermia therapy on local control rate in radio-induced angiosarcoma of the chest wall. Strahlenther Onkol 2013; 189:387-393.

62 Karasawa K, Katsui K, Seki K, et al.: Radiotherapy with concurrent docetaxel for advanced and recurrent breast cancer. Breast Cancer 2003;10:268-274.

63 Semrau S, Gerber B, Reimer T, Klautke G, Fietkau R: Concurrent radiotherapy and taxane chemotherapy in patients with locoregional recurrence of breast cancer. A retrospective analysis. Strahlenther Onkol 2006;182: 596-603.

64 Zagar TM, Higgins KA, Miles EF, et al.: Durable palliation of breast cancer chest wall recurrence with radiation therapy, hyperthermia, and chemotherapy. Radiother Oncol 2010;97:535-540. 
65 Harms W, Krempien R, Hensley FW, Berns C, Wannenmacher M, Fritz P: Results of chest wall re-irradiation using pulsed dose rate (PDR) brachytherapy moulds for breast cancer local recurrences. Int J Radiat Oncol Biol Phys 2001;49:205-210.

66 Vernon CC, Hand JW, Field SB, et al.: Radiotherapy with or without hyperthermia in the treatment of superficial localized breast cancer: results from five randomized controlled trials - International Collaborative Hyperthermia Group. Int J Radiat Oncol Biol Phys 1996;35:731-744.

67 Jones EL, Oleson JR, Prosnitz LR, et al.: Randomized trial of hyperthermia and radiation for superficial tumors. J Clin Oncol 2005;23:3079-3085.

68 Linthorst M, Baaijens M, Wiggenraad R, et al.: Local control rate after the combination of re-irradiation and hyperthermia for irresectable recurrent breast cancer: results in 248 patients. Radiother Oncol 2015;May 19 [Epub ahead of print].
69 Salvadori B, Marubini E, Miceli R, et al.: Reoperation for locally recurrent breast cancer in patients previously treated with conservative surgery. Br J Surg 1999; 86:84-87.

70 Voogd AC, van Tienhoven G, Peterse HL, et al.: Local recurrence after breast conservation therapy for early stage breast carcinoma: detection, treatment, and outcome in 266 patients. Dutch study group on Local Recurrence after Breast Conservation (BORST). Cancer 1999;85:437-446.

71 Ishitobi M, Komoike Y, Nakahara S, Motomura K, Koyama $\mathrm{H}$, Inaji $\mathrm{H}$ : Repeat lumpectomy for ipsilateral breast tumor recurrence after breast-conserving treatment. Oncology 2011;81:5381-5366.

72 Gentilini O, Botteri E, Veronesi P, et al.: Repeating conservative surgery after ipsilateral breast tumor reappearance: criteria for selecting the best candidates. Ann Surg Oncol 2012;19:3771-3776.
73 Deutsch M: Repeat high-dose external beam irradiation for in-breast tumor recurrence after previous lumpectomy and whole breast irradiation. Int J Radiat Oncol Biol Phys 2002;53:687-691.

4 Delanian S, Housset M, Brunel P, et al.: Iridium 192 plesiocurietherapy using silicone elastomer plates for extensive locally recurrent breast cancer following chest wall irradiation. Int J Radiat Oncol Biol Phys 1992;22:1099-1104.

75 Li G, Mitsumori M, Ogura M, et al.: Local hyperthermia combined with external irradiation for regional recurrent breast carcinoma. Int J Clin Oncol 2004;9: 179-183.

76 Kouloulias VE, Dardoufas CE, Kouvaris JR, et al.: Liposomal doxorubicin in conjunction with re-irradiation and local hyperthermia treatment in recurrent breast cancer: a phase I/II trial. Clin Cancer Res 2002; 8:374-382. 